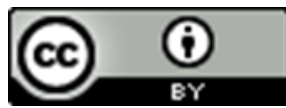

\title{
AS NOÇÕES DE ESPAÇO E TEMPO A PARTIR DE UMA
}

\section{CARTOGRAFIA QUILOMBOLA}

Lourdes Carril ${ }^{1}$

RESUMO: O trabalho com as noções de tempo e espaço na sala de aulas das séries iniciais, do Ensino fundamental, é parte das Diretrizes Curriculares Nacionais ${ }^{i}$, com reformulações na $\mathrm{BNCC}^{\mathrm{ii}}$, esta que deve ser analisada criticamente dada a importância para o desenvolvimento das relações espaciais nessa etapa de formação. Temos nos deparado com desafios que perpassam diversos fatores envolvidos para que esse processo se estabeleça de maneira a que os estudantes compreendam, tanto o papel da história e da geografia na escola, quanto apreendam o sentido da espacialidade e da alteridade na vida social. As várias ideologias, representações e ilusões que incidem na sociedade contemporânea e, portanto, na escola, acabam por reforçar o sentido do espaço social na perspectiva alienante. Lefebvre (2000, p. XXII) questiona: "Haveria uma relação direta, imediata e mediatamente apreendida, portanto, transparente, entre o modo de produção (a sociedade considerada) e seu espaço?" Perguntamos: como se ensina a geografia na sala de aula das séries iniciais? De que maneira a ênfase dada, atualmente, à escrita e à leitura no Ensino Fundamental, se constituindo como aprendizado separado do tempo e do espaço, pode ser reformulada sob outra prática pedagógica, que traga a questão da Cultura Afrobrasileira nessa etapa da educação?

Palavras-Chave: Espaço, Tempo, Alteridade, Cultura Afro-Brasileira.

\section{THE NOTIONS OF SPACE AND TIME FROM A QUILOMBOLA CARTOGRAPHY}

\begin{abstract}
The work with the notions of time and space in the classroom of the initial grades, of elementary school, is part of the National Curriculum Guidelines, with reformulations in the BNCC, which must be critically analyzed given the importance for the development of spatial relationships in this stage of formation. We have faced challenges that pervade several factors involved so that this process is established in a way that students understand, both the role of history and geography in school, and apprehend the sense of spatiality and alterity in social life. The various ideologies, representations and illusions that affect contemporary society and, therefore, the school, end up reinforcing the sense of social space in the alienating perspective. Lefebvre (2000, p. XXII) asks: "Would there be a direct, immediate and immediately apprehended relationship, therefore, transparent, between the mode of production (the society considered) and its space?" We ask: how is geography taught in the classroom of the initial grades? How can the emphasis currently given to writing and reading in

\footnotetext{
${ }^{1}$ Prof. Adjunta do Curso de Licenciatura em Geografia/DGTH - Departamento de Geografia, Turismo e Humanidades, da UFSCar - Universidade Federal de São Carlos, campus Sorocaba. E-mail: lfatimacarril@gmail.com, ORCID: https://orcid.org/0000-0001-6492-1130
} 
elementary school, constituting learning separate from time and space, can be reformulated under another pedagogical practice, which brings the question of AfroBrazilian Culture in this stage of education?

Keywords: Space, Time, Alterity, Afro-Brazilian Culture.

\section{LAS NOCIONES DE ESPACIO Y TIEMPO DE UNA CARTOGRAFÍA QUILOMBOLA}

Resumen: El trabajo con las nociones de tiempo y espacio en el aula de los grados iniciales, de primaria, es parte de los Lineamientos Curriculares Nacionales, con reformulaciones en el BNCC, que deben ser analizados críticamente dada la importancia para el desarrollo de las relaciones espaciales. en esta etapa de formación. Nos hemos enfrentado a desafíos que impregnan varios factores involucrados para que este proceso se establezca de manera que los estudiantes comprendan, tanto el papel de la historia como la geografía en la escuela, y aprehendan el sentido de espacialidad y alteridad en la vida social. Las diversas ideologías, representaciones e ilusiones que afectan a la sociedad contemporánea $\mathrm{y}$, por tanto, a la escuela, acaban reforzando el sentido de espacio social en la perspectiva alienante. Lefebvre (2000, p. XXII) pregunta: ¿¿Habría una relación directa, inmediata y aprehendida inmediatamente, por tanto, transparente, entre el modo de producción (la sociedad considerada) y su espacio?" Nos preguntamos: ¿cómo se enseña la geografía en el aula de los grados iniciales? ¿Cómo se puede reformular el énfasis que se le da actualmente a la escritura y la lectura en la escuela primaria, que constituye un aprendizaje separado del tiempo y del espacio, bajo otra práctica pedagógica, que trae la cuestión de la cultura afrobrasileña en esta etapa de la educación?

Palabras clave: Espacio, Tiempo, Alteridad, Cultura afrobrasileña.

\section{LES NOTIONS D'ESPACE ET DE TEMPS À PARTIR D'UNE CARTOGRAPHIE QUILOMBOLA}

Résumé: Le travail sur les notions de temps et d'espace dans la salle de classe des premières années, du primaire, fait partie des National Curricular Guidelines, avec des reformulations au BNCC, qui doivent être analysées de manière critique compte tenu de l'importance pour le développement des relations spatiales à ce stade de la formation. Nous avons été confrontés à des défis qui imprègnent plusieurs facteurs impliqués afin que ce processus s'établisse d'une manière que les élèves comprennent, à la fois le rôle de l'histoire et de la géographie à l'école, et appréhendent le sens de la spatialité et de l'altérité dans la vie sociale. Les diverses idéologies, représentations et illusions qui affectent la société contemporaine et, par conséquent, l'école, finissent par renforcer le sens de l'espace social dans une perspective aliénante. Lefebvre (2000, p. XXII) demande: "Y aurait-il un rapport direct, immédiat et immédiatement appréhendé, donc transparent, entre le mode de production (la société considérée) et son espace?" Nous demandons: comment la géographie est-elle enseignée dans la classe des premières années? Comment l'accent mis actuellement sur l'écriture et la lecture à l'école élémentaire, constituant un apprentissage séparé du temps et de l'espace, peut-il être reformulé sous une autre pratique pédagogique, qui pose la question de la culture afrobrésilienne à ce stade de l'éducation? 
Mots clés: espace, temps, altérité, culture afro-brésilienne.

\section{INTRODUÇÃO}

Iniciamos indicando uma das principais alienações impostas ao cotidiano escolar, a de que seria possível ler o mundo pelo domínio do código da linguagem, separado do vivido corporal e da construção da espacialidade, sendo que a condição histórica para a humanização e à construção dos conhecimentos realizados no processo civilizatório teve o sentido contrário.

No processo da formação docente, a separação das ciências em campos distintos acaba por dificultar a elaboração de uma visão social totalizante, na verdade, demonstrando que os professores ao passarem por uma formação fragmentada, acabam por reproduzir os procedimentos didáticos e pedagógicos que vivenciaram, muitas vezes, sem a devida consciência crítica. Na educação geográfica, a tarefa de ensinar geografia aos ciclos I e II das séries iniciais foi atribuída aos formandos em Pedagogia, e aos licenciados em Geografia os demais ciclos e séries. Essa separação que está presente na formação docentes constitui-se também no nível dos conhecimentos curriculares, uma espécie de divisão entre aqueles que sabem ensinar (do ponto de vista pedagógico) e os que dominam o conhecimento científico (licenciados nas diversas disciplinas).

As experiências de tempo e o espaço nos mostram essa problemática, na medida em que tempos e espaços são propícios à arte e à criação, também. Historicamente, cada vez mais os indivíduos se veem deslocados dos lugares e de experiências temporais aos quais estavam inseridos, havendo perda de domínio do tempo da criação, do ócio e da subjetividade. Comportamentos prescritos segundo as representações do espaço e tempo hegemônicos e consumo dirigido envolvem todo o tecido social. Os indivíduos vão lidando com uma sociedade que a eles impõe certo número de tarefas, tanto materiais quanto de ajustes psíquicos, que passam, também, pela questão dos padrões existentes do ser e existir.

Nas sociedades modernas, a diferença ora incomoda e se traduz em marginalidade e estigmatiza o outro, vinculando à imagem do outro à desconfiança. Segundo Lima (2000), em nossa experiência contemporânea, perdemos a válvula de ajuste que as sociedades consideradas tradicionais asseguravam aos considerados 
"marginais", os mesmos, segundo o autor, podiam ser xamãs e feiticeiros, por exemplo. No capitalismo tardio, em que padrões de homogeneidade identitária afetam as subjetividades, há o esforço interiorizado do sujeito de ser aceito e reconhecido: “a única coisa que permanece inalterável ao curso da vida é o processo de esforçar-se e de prestar atenção aos sinais vindos dos outros”. (LIMA, 2000, p. 52).

Propomos, neste trabalho, refletir sobre a construção das noções de tempo e espaço na formação docente, das primeiras séries, na educação básica, analisando a construção da espacialidade a partir do corpo de si e do outro, sustentando que essas primeiras noções são importantes para o acolhimento das diferenças existentes na vida social e procurando ir ao encontro da legislação: Lei 10.639/03 e 11.745/08 iii, que tornou obrigatório ensino de História da África, Cultura Afrobrasileira e Indígena na escola. Esse esforço reflexivo se pauta em nossa atuação junto aos estudantes do ensino superior nos cursos de pedagogia e geografia, na busca de uma pedagogia significativa à trajetória formativa das crianças, que possibilite a construção do significado do espaço e tempo. Analisa-se a cartografia enquanto ferramenta que se pode utilizar para a representação espacial de forma articulada aos diferentes sujeitos. Nessa perspectiva, os conhecimentos geográficos e históricos presentes não se destacam da realidade vivida em suas diferentes espacialidades, permitindo a visibilidade dos sujeitos que portam diferentes modos de ser e que compreendem a pluralidade social.

Por fim, apresentamos a construção de maquetes como experiência do encontro do Eu e do Outro, realizadas com a comunidade quilombola Cafundó, localizada em Salto de Pirapora-SP, como ensaio didático-pedagógico buscando as representações do espaço e os espaços de representação (LEFEBVRE, 2000). O espaço de representação parte da experiência da espacialidade originária na experiência do sujeito, sendo espaço simbólico que perpassa o espaço vivido e o projeta no mundo. Desta maneira, é necessário articular o conhecimento do espaço à prática social e em sua materialidade imediata. Na cartografia que, muitas vezes, é levada à criança e aos estudantes, é um equívoco partir-se da geometrização do plano, normatizado pela simbologia e códigos do mapa, tornando as representações cartográficas um instrumental de difícil acesso à compreensão daquilo que é vivido e percebido no cotidiano e está ausente na representação do mapa.

Nesse sentido, reconhecer, mais do que o saber da criança, a percepção de si e do seu corpo como referência central para a relação com o existente é fundamental para 
a busca de metodologias que, partindo da reflexão do que somos e podemos ser tem relação com os espaços sociais e os circuitos do afeto ${ }^{\text {iv }}$. Perguntamos, dessa forma: como proporcionar uma didática que realize não somente o conhecimento espacial, mas que este seja um caminho para o pensar a si e os outros? Esse processo seria suporte para que as crianças se sintam acolhidas em discutir o mundo da forma como o vivenciam e aprenderem a questioná-lo.

É preciso pensar que a compreensão da passagem do tempo e a experiência do viver o lugar aparece decorrente do ser/estar no mundo na longa separação humanidade natureza. Tanto a geografia quanto a história abarcam em seu escopo epistemológico as categorias tempo e espaço. Contudo, estas não devem se fechar em conceitos apreendidos formalmente na sala de aula, mas em processos de vivências, no caminhar, luta e repouso, que trouxe a criação de artefatos de dominação da escassez (SANTOS, 2006). Segundo o autor, o avanço da técnica levou os indivíduos a se afastarem cada vez mais da unidade com a natureza, seguindo-se outras tantas separações na contemporaneidade. É nessa perspectiva que, muitas vezes, o trabalho escolar com as espacialidades, compreendendo suas especificidades, contribui ao horizonte de desvendamento das alienações e das coerções socioespaciais.

No processo de socialização humana, construíram-se conhecimentos que se ampliaram para além das fronteiras vividas, considerando o espaço (social), assim como o tempo (social), não mais como fatos da "natureza" mais ou menos modificada, nem como simples fatos de "cultura", mas como produtos (LEFBVRE, 2000, p. XIX). O espaço tomado como um conjunto conceitual difuso, natural, cosmológico, espaços conquistados, ocupados, o espaço material, concreto, metrificado, geometrizado, se torna uma abstração, para esse autor. As abstrações espaciais que ora discutimos encontram-se fazem parte do início da Modernidade, quando se superou a ideia de que a terra seria plana, ideologia da cristandade medieval, e quando expedições comandadas pelas coroas europeias se aventuraram pelos mares. Obviamente, essa expansão esteve, particularmente, atrelada às necessidades da classe social emergente, a burguesia comercial. Assim, a invenção da perspectiva, na Toscana, nos séculos XIII e XIV, trouxe consigo a possibilidade de ser pensado o mapa e sua geometria moderna.

Nos séculos XV e XVI, o espaço euclidiano é necessário à pontuação do globo terrestre, à identificação da extensão espacial e à localização de espaços distantes. A partir do que há o desenvolvimento da cartografia moderna, mapas portulanos, cartas, 
efetivando, gradativamente, a produção e controle do espaço. Se tornam mais eficientes as conquistas e ocupações territoriais e as novas fronteiras nacionais que se seguiram, a lógica do comércio e da indústria leva à produção de espaços e territórios conhecidos e cartografados. Espaços de apropriação, explorações, intervenções e planificações, o campo e a cidade, uma segunda natureza, maior abstração, mas e os espaços de usos e representações mentais?

O conceito de espaço reúne o mental e o cultural, o social e o histórico. Reconstituindo um processo complexo: descoberta (de espaços novos, desconhecidos, continentes ou o cosmos) - produção (da organização espacial própria a cada sociedade) - criação (de obras: a paisagem, a cidade como a monumentalidade e o décor). Isso evolutivamente, geneticamente (com uma gênese), mas segundo uma lógica: a forma geral da simultaneidade; pois todo dispositivo espacial repousa sobre a justaposição na inteligência e na junção material de elementos dos quais se produz a simultaneidade..."? (LEFEBVRE, 2000 , p. XII) ${ }^{\mathrm{v}}$.

A questão apresentada por Lefebvre se apresenta fundamental para se pensar metodologias do ensino histórico e geográfico que articulem os atributos antropológicos, numa perspectiva oposta aos dos tempos e espaços homogeneizados, construindo uma relação próxima com o mundo e com o outro.

As relações espaciais se processam desde o nascimento e se aproximam do lugar em que a criança vive, onde passa a constituir as noções de mundo. Essas noções são apreendidas no plano da vivência e das representações; na educação infantil, inicia-se o desenvolvimento das primeiras noções de espaço e nos anos iniciais do ensino fundamental se ampliam os conceitos básicos desenvolvidos na escola.

O aprendizado do mapa e o entendimento das noções de lugar, paisagem, território, categorias conceituais importantes à geografia, passa por experiências escolares fundamentais à compreensão da importância do sujeito na construção dos saberes que, no caso da geografia, se encontram na possibilidade de leitura da realidade espacial.

Contudo, não se trata de olhar à volta e realizar essa leitura, o que seria o mesmo que apresentar um mapa representando um determinado fenômeno sem trabalhar as representações que se encontram nas crianças. Na educação das séries iniciais, é possível levar à frente o desenvolvimento da noção de realidade espacial corporal, uma metodologia de apropriação de si e das capacidades de apreensão das coisas que se 
relacionam com o Eu e o Outro. A centralidade do corpo como identificação com a espacialidade corresponderia à percepção da presença, extensão e projeção do corpo espacialmente. $\mathrm{O}$ olhar espacial, dessa forma, não supõe de imediato desencadear o estudo de determinada realidade social verificando as marcas inscritas nesse espaço, nas séries iniciais, significa entender a própria ideia de espaço e de que somos parte e ao mesmo tempo representamos uma ruptura com o todo.

A representação do espaço é uma ação interiorizada. Conforme Almeida (2001, p. 71), a evolução da representação ocorre da seguinte forma:

Primeiro estabelece-se a atividade sensório-motriz elementar; depois surge a ação ligada à imaginação, a qual só é possível após ter sido realizada materialmente; depois, a coordenação das ações exteriores amplia-se, o que repercute também em uma coordenação interna (articulação progressiva das intuições); mais tarde, formam-se as operações concretas que resultam dessa articulação. A construção do pensamento da criança dá-se pela ação. Inicialmente, o espaço é para ela quase incompreensível e sua conquista ocorre de forma gradativa, à medida que sua percepção espacial avança qualitativamente. Por isso é relevante que a criança aja sobre o espaço para compreendê-lo (ALMEIDA, 2001, p. 71).

A ação sobre o espaço constitui a busca da criança pelo controle do espaço, um processo pelo qual passa para compreender a sua presença e a do outro, que é a própria espacialidade, percebendo o espaço vivido, do movimento e do deslocamento. Mas, tal abordagem não pode se descolar da reflexão sobre as funções cognitivas complexas de um sujeito contextualizado e, portanto, histórico (VYGOTSKY, 2011). Por isso, o processo caminha para experimentar o espaço não só a partir do processo interno ao indivíduo, mas da necessidade de sua relação com os demais sujeitos sociais. Pensar sobre uma área retratada em um mapa, mesmo que não a conheça, é um processo que tem como base a construção da noção de espaço como processo social. Quando a criança compreende o espaço a partir do vivido e de sua percepção como elemento existente entre si, a natureza e os demais, praticando e representando o espaço, pode-se dizer que teve início para ela o estudo da Geografia, daí a importância de o professor propor atividades que auxiliem no desenvolvimento das noções espaciais.

Por isso, a escola, ao trabalhar com a representação do espaço de modo abstrato ou como um conhecimento pronto e acabado, deixa de constituir a possibilidade de desconstruir as reificações da vida social, pelo contrário, instituindo-as no processo do conhecimento. Nesse sentido, o fundamental para os estudantes seria construírem o 
conceito de mapa a partir de si indo ao encontro das várias alteridades, entendendo que se trata de uma forma de representar os vários corpos, abarcando domínios fundamentais das relações espaciais topológicas, projetivas e euclidianas, como dispositivo científico e tecnológico construídos nas sociedades modernas.

\section{PROJETO QUILOMBO DO CAFUNDÓ: O EU E O OUTRO QUILOMBOLA}

Desenvolvemos o projeto na disciplina Metodologia e Prática do Ensino de História e Geografia, do $7^{\circ}$. Semestre do curso de Pedagogia, nos primeiros semestres de 2014 e 2016. O projeto teve como objetivo central identificar modalidades de uso do espaço e do tempo a partir da história da Comunidade Quilombola Cafundó - Salto de Pirapora/SP. A partir da elaboração de leituras teóricas, do levantamento de dados e informações sobre o território quilombola, foi realizado um caderno de campo (figura1) em que constavam os levantamentos preparatórios para o trabalho de campo.

Figura 1 - Caderno de Campo - Visita ao Quilombo do Cafundó Não é discutir o que foi, e sim discutir o que é e como essa autonomia foi sendo construída historicamente. (A. W. B. de Almeida)

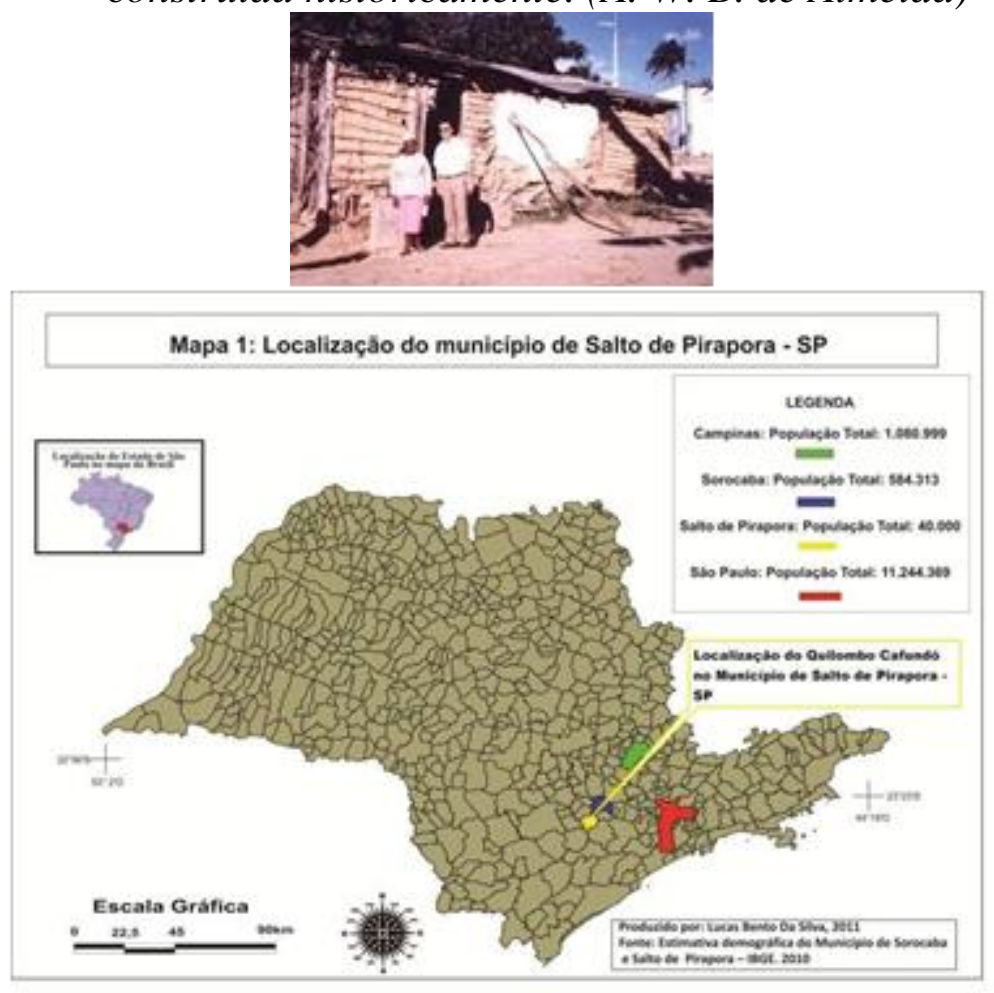

Fonte: Reportagem de Sérgio D’ Ávila na Folha de São Paulo de 14/05/1995

Segundo Vogt e Fry (1996), a história do Cafundó se remete à doação de terras a 
um casal de escravos libertos - Joaquim Congo e Ricarda. Eles receberam, em 1888, a doação de um lote de terra de seu antigo dono, antigo senhor, José Manoel de Oliveira, sendo que, posteriormente, o casal teria trocado as terras doadas pela área onde hoje se situa a comunidade. As duas filhas de Ricarda e Joaquim Congo - Antônia Efigênia -, que permaneceram morando no Cafundó, constituíram dois grupos de parentes: os Almeida Caetano e os Pires Cardoso. Essa divisão ainda se encontra presente na disposição das casas da comunidade. As casas de pau-a-pique, com o chão de terra batida e uma capela são as construções mais antigas. Somente a partir de 1980, as casas de alvenaria foram construídas com a ajuda financeira de diversas entidades e do poder público local.

Mediante a visita e entrevista com moradores quilombolas do Cafundó, percebemos alguns costumes e vivências culturais, como moradias de taipa cobertas de sapé, fogões a lenha e cura por ervas, além da língua, de origem bantu, a cupópia, permanece. Uma das experiências religiosas revigoradas pela comunidade é o candomblé, a qual faz parte das ancestralidades afro-brasileiras. A capela da comunidade (figura 2), possui imagens de santos católicos e do candomblé, além da presença de fotografias de pessoas falecidas (figura 3), antigas moradoras do lugar. É em torno dessa capela que, no mês de maio, realiza-se a Festa de Santa Cruz (figuras 4 e 5), da qual participam, além dos moradores da comunidade, outras pessoas que vêm de foram, de locais próximos e mais distantes. Nessa festa, que ocorre no mês de maio, é comemorada, também, a abolição da escravatura, tendo a celebração de uma e a apresentação da dança típica - o Jongô.

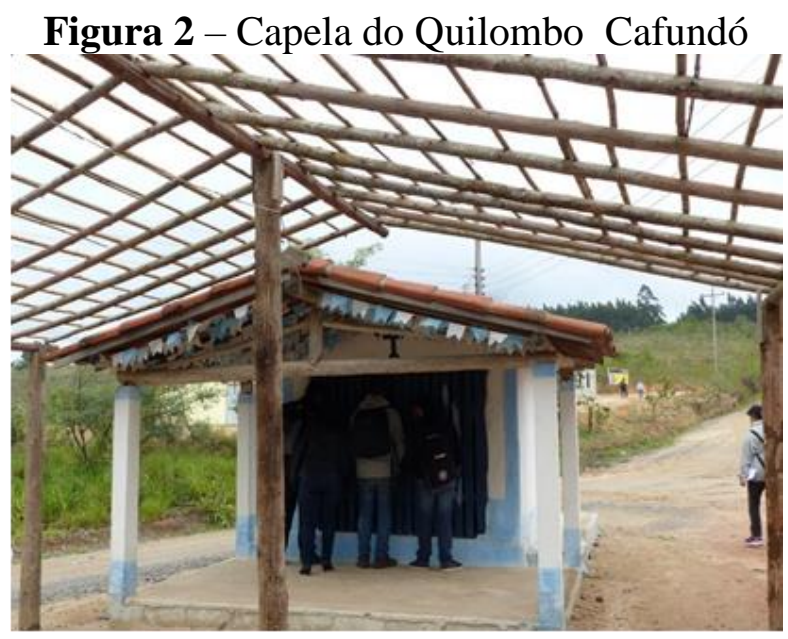

Fonte: Autora 
Figura 3 - Fotos de Pessoas Falecidas do Cafundó

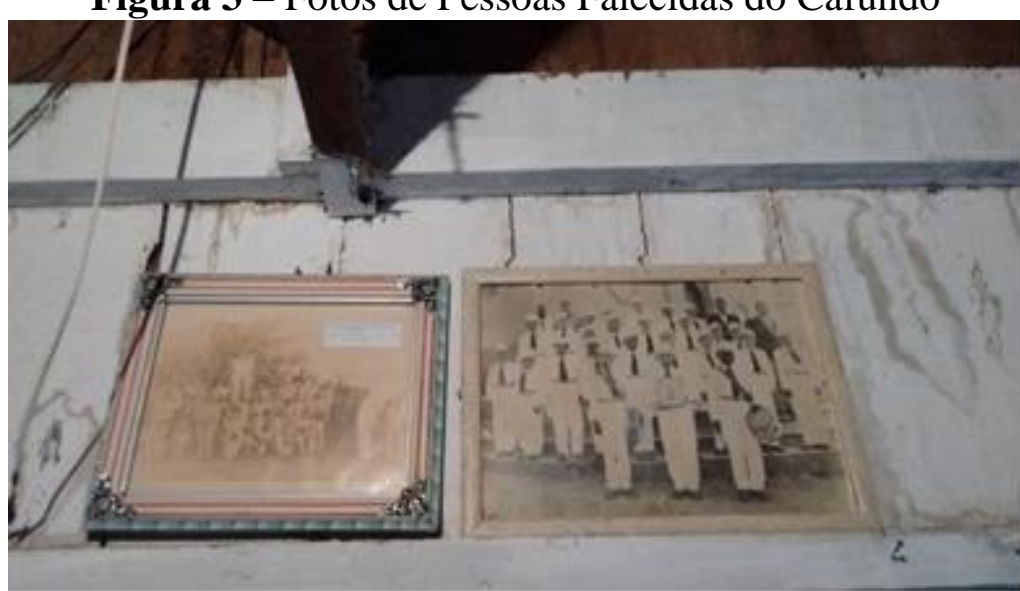

Fonte: Autora

Figuras 4 e 5 - Levantamento do Mastro na Festa de Santa Cruz
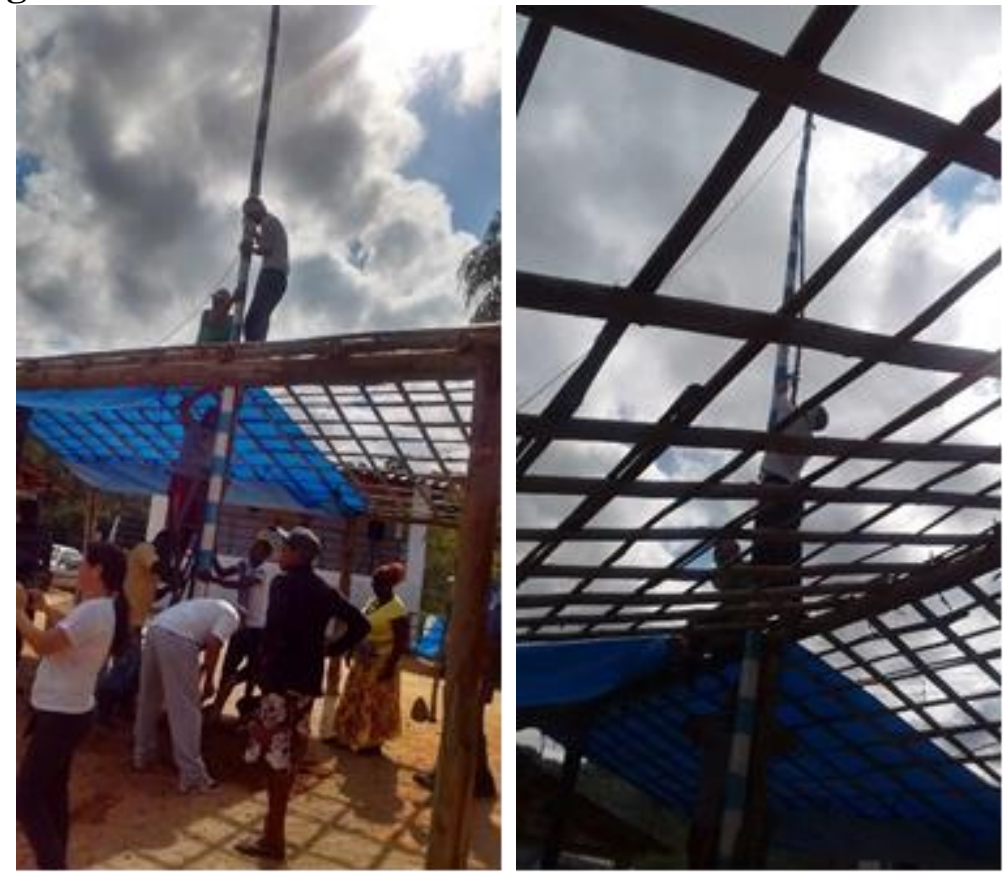

Fonte: Autora

Os moradores do Cafundó atuam em diversos trabalhos como: pedreiros, jardineiros, caseiros e cortadores de eucalipto. As mulheres trabalham, muitas delas, como diaristas em propriedades da região. Enquanto as roças são destinadas apenas para o consumo interno, plantando-se o feijão, o milho e a mandioca. Criam-se animais, como: galinhas, porcos e gado, e cada família é responsável por manter os cuidados necessários na roça e com os animais (figura 6) 
Figura 6 - Horta Comunitária do Quilombo do Cafundó

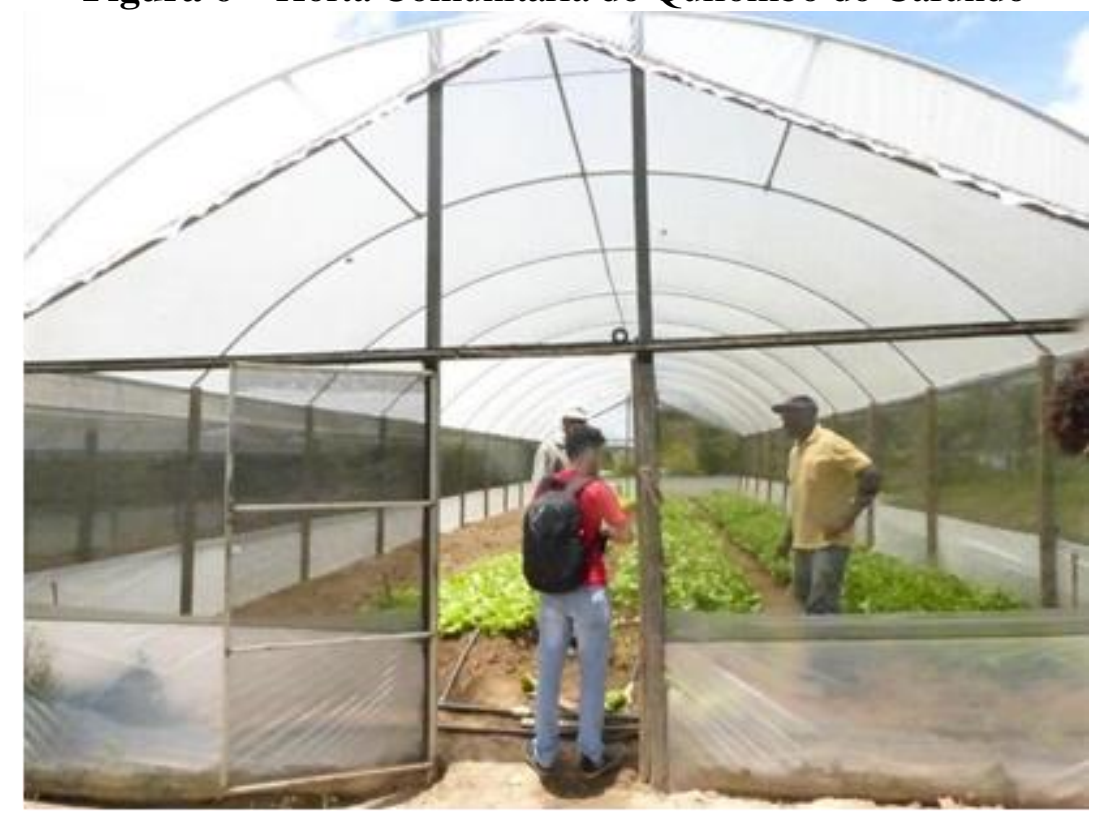

Fonte: Autora

Um dos principais patrimônios da cultura do Cafundó é o dialeto conhecido como falange ou cupópia, que possui 140 palavras, aproximadamente. A maior parte, tendo origem na língua africana chamada quimbundo, da família banto, falada, principalmente, em Angola.

Segundo Fry e Vogt (1996) o uso da língua se dá através de um “aportuguesamento", sobretudo, quanto à estrutura sintática, também, ao uso de palavras da língua portuguesa no meio da frase. Essa língua é falada em situações diversas: quando se quer dizer algo em segredo - na frente de pessoas que desconhecem a língua-, em diálogos cotidianos ou ainda quando é ensinada às crianças da comunidade. Entendese que é uma importante forma de preservação da identidade cultural da comunidade.

Outro aspecto relevante do trabalho de campo é o de que a escola que serve à comunidade Cafundó, se situa, num bairro vizinho, a oito quilômetros de distância e, no qual, um ônibus escolar busca os estudantes na porteira da comunidade. Quanto à saúde, não há postos próximos à comunidade. Assim, o único atendimento à comunidade se restringe a uma visita semanal de um médico do Programa Saúde da Família.

\section{O RECONHECIMENTO DA COMUNIDADE}

O território do Cafundó, atualmente, dividido em quatro áreas, apresenta uma complexidade, fruto do processo de grilagem sistemática, com ênfase a partir de 1960, o momento a partir do qual se intensificam os conflitos e a violência contra a comunidade. 
Esse processo de negação das terras de quem realmente é dono, que atinge os quilombolas, indígenas e outros, se contextualiza em um processo de exclusão étnica, racial social e histórica (SILVA,2011). A comunidade que tem seu território reconhecido em uma área total de 218,4 Hectares, durante muito tempo, teve a maior parte desses hectares em posse de grileiros, e desabitadas. O processo de regularização foi iniciado com o relatório técnico/antropológico produzido pela Fundação Instituto de Terras de São Paulo (ITESP), em 1999, e teve continuidade com a edição do Decreto 4887/2003, pelo INCRA, todo o processo amparado pela Constituição de 1988. Finalmente, em 19 de novembro de 2014, a liderança da comunidade, Regina, recebeu das mãos da Presidente da República, Dilma Rousseff, o CCDRU do território do Cafundó, tendo sido assinado em 26 de novembro. O Contrato de Concessão de Direito Real de Uso (CCDRU) lhes assegura a posse sobre as áreas que ocupam e é um documento de caráter provisório que resguarda os direitos dos interessados até o julgamento da ação em que se busca a titulação definitiva do território ${ }^{\text {vivi }}$.

\section{A CONSTITUIÇÃO DA DIFERENÇA E DA IDENTIDADE}

O reconhecimento da diferença e das identidades é uma importante discussão nas sociedades multiculturais, como a brasileira, principalmente, quando políticas públicas passaram a tornar obrigatório o tema da diversidade nos currículos, sobretudo, na educação para as elações étnicas e raciais ${ }^{\mathrm{V}}$. Esse processo ainda está longe de ter sido incorporado pelos currículos e pelas práticas pedagógicas escolares, de forma contínua, e, por isso, é preciso debater a necessidade de que as escolas desenvolvam projetos pedagógicos que possam discutir a formação da sociedade brasileira, segundo as suas singularidades culturais, sociais, étnicas, de gênero e sexualidade. A abertura do currículo escolar brasileiro para a História da África e Cultura Afro Brasileira assegurou na educação básica, incluindo a educação infantil, o trabalho com a diversidade e a desconstrução das identidades universais, padronizadas segundo modelos hegemônicos da sociedade e centradas na visão das elites, além de combater qualquer tipo de preconceito e discriminação racial na escola e na sociedade.

Os temas da identidade e da diferença têm sido discutidos na sociedade atual, sob diversas perspectivas, do multiculturalismo, das teorias críticas, pós- coloniais ou estudos culturais, também, têm sido realizadas propostas práticas pedagógicas pelos 
professores, até entre as pedagogias tradicionais, etc. Para Silva (2013), mais do que positivar a identidade, é importante entender a identidade e a diferença a partir de uma produção social e não como aspectos essenciais aos sujeitos, o que acaba por naturalizar a diferença, mas ambos conceitos ser entendidos de forma interdependente. Em outras palavras, as identidades só existem por se referirem à própria diferença. Nesse sentido, as afirmações sobre diferença dependem, assim, "de uma cadeia, em geral oculta, de declarações negativas sobre (outras) identidades. Assim como a identidade depende da diferença, a diferença depende da identidade. Identidade e diferença são, pois, inseparáveis" (SILVA, 2000, p. 73).

Essa questão trazida para a nossa discussão propicia pensar sobre a construção de uma sociedade democrática e passa pelas práticas pedagógicas escolares. Na escola, é possível trabalhar a diferença e a identidade desde a educação infantil, buscando experiências de interação social entre grupos diversos que levem ao conhecimento de si e ao respeito ao outro.

Nesse sentido, a identidade será subjacente a esse processo, algo que vai sendo construído. Segundo Mezan (1986), todos nós temos um sentimento de identidade, isto é, a sensação subjetiva de que algo subjaz aos diversos momentos de nossa existência e os torna parte da mesma vida, a de cada um de nós. A percepção de continuidade, fronteiras e identidade são parte de nossa formação corporal e psíquica:

Estes fenômenos podem parecer naturais, mas não são: existem pessoas cuja perturbação psíquica concerne exatamente a estas sensações de permanência, de continuidade, de poucos limites claros entre si e outros; tais pessoas podem apresentar sintomas muito variados, que indicam estar pouco estruturado o nível de identidade, neste sentido que estou assinalando (MEZAN, 1986, ps. 44 e 45).

O processo pedagógico que aqui discutimos foi realizado com o intuito de abarcar a questão das noções de espaço e tempo, envolvendo a formação do sujeito na construção do conhecimento das diferentes relações histórico temporais e espaciais. A pesquisa sobre a comunidade quilombola Cafundó foi proposta como referencial de alteridade. Trabalhar as espacialidades, por meio da diferença, constitui um meio de repensar os estigmas que recaem sobre as comunidades afro-brasileiras, significando verificar o quanto de nossas identidades se forjam pela atribuição do negativo àquele que é diferente, e desvendar o processo histórico que trabalha essa negatividade como parte da manutenção de normas sociais que atuam a favor de grupos específicos, em 
detrimento de outros.

\section{O PRECONCEITO RACIAL NO AMBIENTE ESCOLAR ${ }^{\text {viiVII }}$}

E quando eles desceu, ele já desceu assim...chorando né, não queria nem conversar muito. Só quando ele chegou na casa que ele falou que ele passou mal e vomitou na sala de aula e a professora xingou ele, chamou ele de porco, fez ele limpar, ficou ridicularizando ele na frente das outras crianças e aquilo piorou. Mas, assim, o menino já não tava bem, ele ficou mais nervoso, fez cocô na roupa, e a professora esculachou com o menino na sala de aula.

E aí calhou que eu estava de férias, e eu tava aqui nesse dia. Quando ela veio e contou, e eu falei: Óh, mas isso não pode ficar assim, né, então vamô amanhã, eu vou junto com você lá e já vamô conversar com a diretora, não vamô nem conversar com a professora.

É porque vocêis aí do Cafundó, voceis são muito folgado, porque qualquer coisinha voceis já podem vim fazê baderna na escola (Fala da diretora da escola do garota para a Regina ao conseguir o primeiro contato telefônico).

(...) porque eles iam pra escola e ouvia, qualquer coisinha era: Porque é os negrinho do Cafundó. Ah, porque esse pessoal fala uma língua estranha. Entendeu?

(...) E o menino, né, criança, ele não quis ir pra escola mais, e falou que enquanto aquela professora tivesse lá ele não iria.

Segundo Horta (2014), a criança, em questão, é negra e moradora da comunidade quilombola do Cafundó, a qual é bastante estigmatizada no município de Salto de Pirapora. A criança tem seis anos e estava na última fase da educação infantil.

Essa narrativa foi obtida mediante a história oral, metodologia utilizada para trabalhar com o projeto do Cafundó pelos estudantes da Pedagogia. Diante da perspectiva de auto declaração quilombola e das reivindicações dos movimentos sociais negros pela regulamentação dos territórios, juntamente com a problemática conceitual que se apresenta perante a autodenominação dos grupos de "remanescentes de quilombo", cresce a necessidade de se manter aberta a porta de entrada para a discussão da memória. São as solicitações do presente que fazem com que seja imprescindível questionar o papel da memória dessas comunidades e a sua possibilidade de futura 
sobrevivência em meio à aceleração do tempo histórico. Segundo Santos (2006), a globalização se difunde segundo a hegemonia do capital e da tecnologia - o tempo mundo - enquanto os lugares são modificados de forma acelerada e os sujeitos que não se tornam rápidos são invisibilizados.

A memória torna-se, nesse processo, um importante suporte às resistências e práticas territoriais, como as presentes no Quilombo do Cafundó, endo em vista o avanço da urbanização na Região Metropolitana de Sorocaba, da qual faz parte o município de Salto de Pirapora. Segundo Meneses, a memória está em uma eterna relação com o tempo presente: “A elaboração da memória se dá no presente e para responder a solicitações do presente. É do presente, sim, que a rememoração recebe incentivo, tanto quanto as condições para se efetivar" (MENESES, 1992, p. 22). Ou seja, ao contrário do uso corrente que se faz do termo memória, a memória não traz a história, pois é constantemente reelaborada, mutável através do tempo, sendo permeada pelas condições presentes:

A memória não dá conta do passado, nas suas múltiplas dimensões e desdobramentos. E não só, é claro, porque sabemos muito mais do que as memórias vivenciadas no passado poderiam saber, mas, sobretudo, porque o conhecimento exige estranhamento e distanciamento (MENESES, 1992, p. 12).

Ora, surge a questão: se a memória é mutável através do tempo e é carregada de subjetividade, qual seria então a contribuição da memória, reelaborada através da História oral, para o conhecimento histórico? Resposta apropriada fornece Alberti: "A História oral permite o registro de testemunhos e o acesso a 'histórias dentro da História' e, dessa forma, amplia as possibilidades de interpretação do passado.” (2014, p. 155). Preparação da maquete

Foram realizadas atividades corporais durante duas aulas a partir do desenho do corpo e realizadas narrativas de histórias individuais com o objetivo de delimitar a transição das fronteiras do $\mathrm{Eu}$ e do Outro. Sendo tiradas medidas do corpo, primeiramente, de forma livre e depois, com medidas extraídas com fitas métricas, foi feita a primeira representação espacial a partir do que se estabeleceu o diálogo com as representações do espaço e os espaços representados.

Nas duas aulas seguintes, foram feitas as maquetes, dividindo-se a sala em grupos, cada qual elaborando a síntese da atividade de pesquisa sobre a comunidade do 
Cafundó, desde o início do semestre, passando pela ida ao campo, até o trabalho final.

Figura 7 - Maquete Quilombo Cafundó

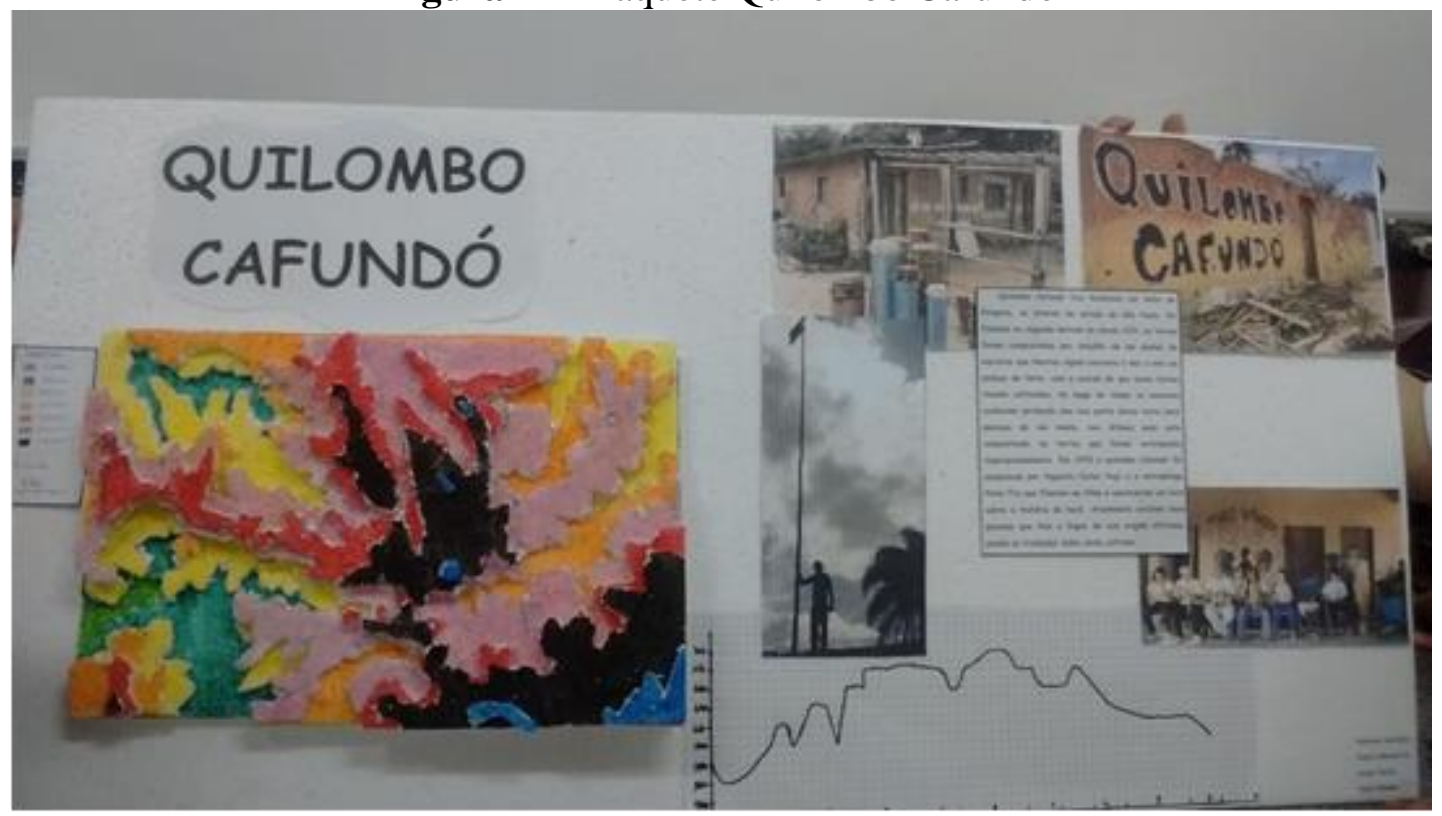

Fonte: Autora

Figura 8 - Maquete do Cafundó

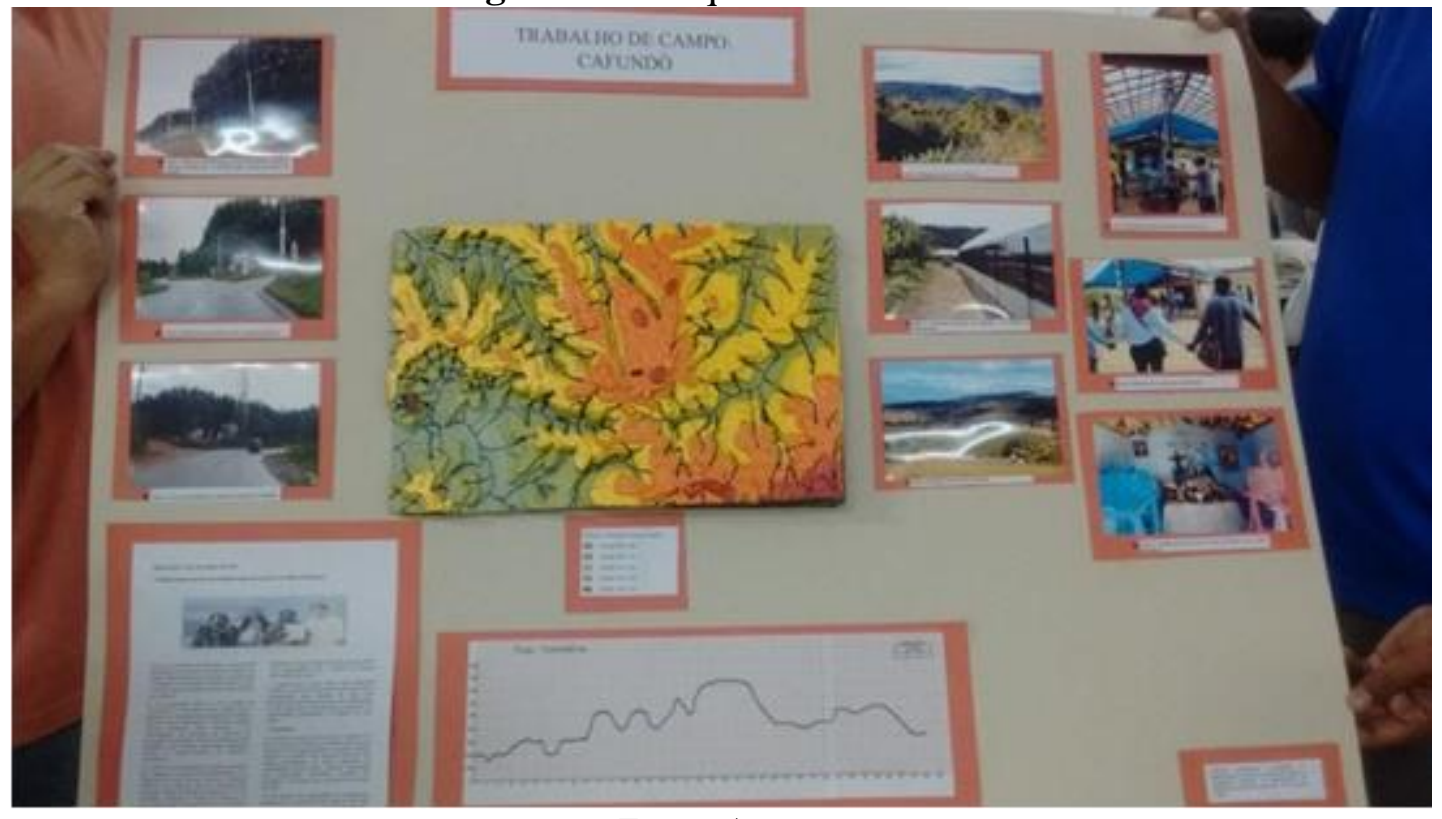

Fonte: Autora 
Figura 9 - Maquete do Cafundó

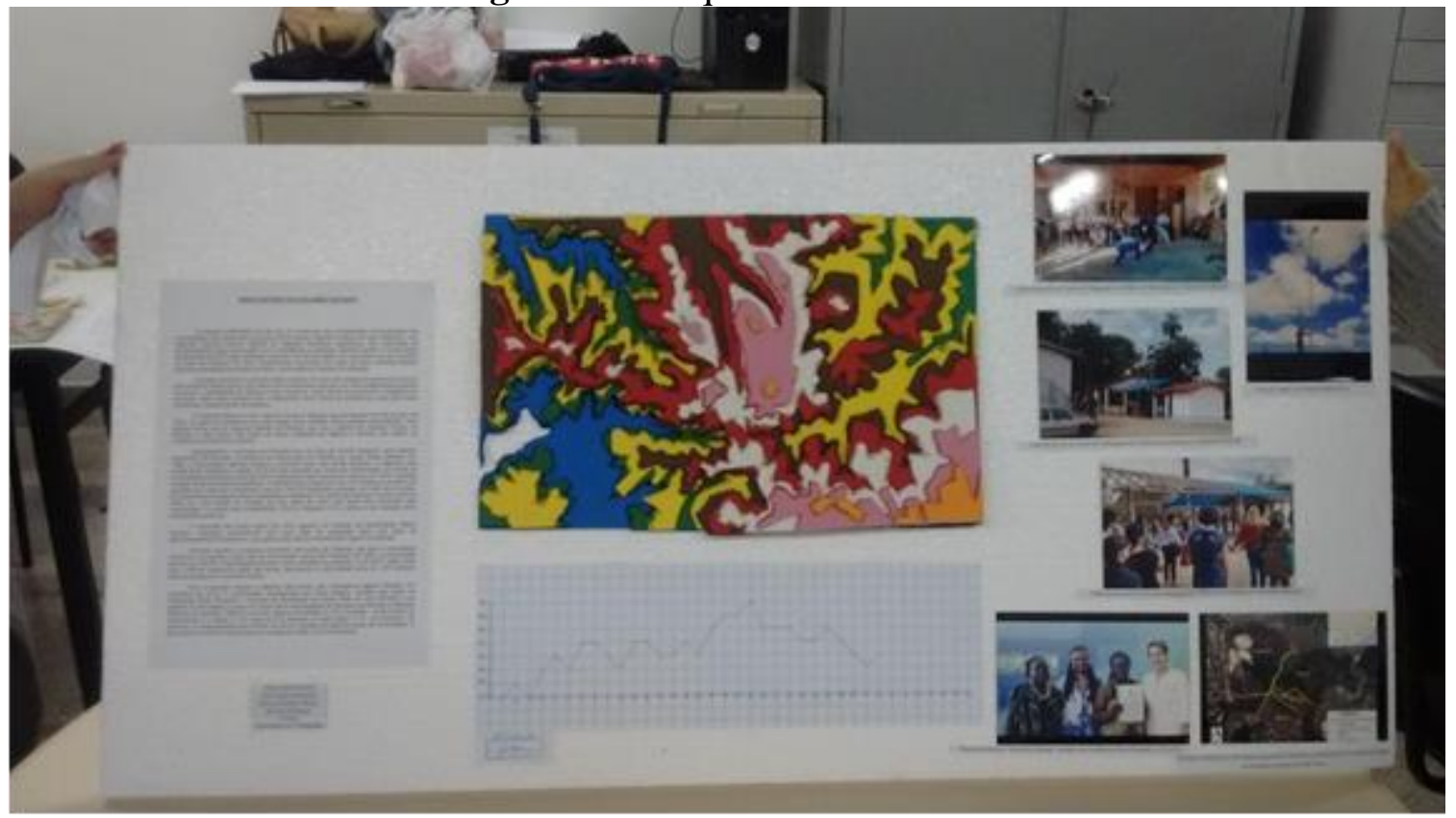

Fonte: Autora

O painel com a maquete junto às narrativas coletadas em trabalho de campo foi o resultado de avaliação da disciplina, sendo, também, apresentado à comunidade quilombola. Nessa perspectiva, importante assinalar que a atividade cartográfica foi feita com base em escala, o que permitiu representar a comunidade situada entre o Rio Sarapuí e o município. Foi extraído um quadrante de um mapa base cartográfica do município de Salto de Pirapora e, a partir dele, trabalhado o território em que os moradores do quilombo vivem. A questão da escala foi construída durante o processo como parte das reflexões sobre o corpo e a construção da espacialidade, procurando delimitar, tanto o corpo do estudante do curso, quanto o corpo do quilombo, buscando entender que a espacialidade pertence ao âmbito da relação entre o Eu e o Outro, constituídos nas relações sociais e que a escala é o próprio sujeito. O corpo de cada estudante foi, antes disso, desenhado pelo seu colega e, vice-versa, além de serem efetuadas atividades de narrativas de vida pelos mesmos, tendo em vista que os próximos passos seria cartografar o quilombo e, dessa feita, suas narrativas. Nas atividades seguintes, foram realizados o trabalho de campo e a síntese aqui trazida por algumas fotografias de painéis feitos pelos alunos.

Conforme Marisa Fernandes dos Santos (2020), a temática étnico racial tem proporcionado novas interpretações teórico metodológicas na geografia, como foi demonstrado aqui com as narrativas e referências da quilombo, a escola e o universo da 
educação. As categorias de análise, tempo e espaço, receberam importantes elementos, características, usos e relações a partir das experiências e diálogos dos estudantes e moradores do quilombo, portanto, protagonismos que não estão centrados no pensamento geográfico clássico, são ideias e reflexões que estão no chão da terra (OLIVEIRA, 2016).

\section{CONSIDERAÇÕES FINAIS}

Este trabalho buscou apresentar uma discussão sobre a construção das noções de espaço e tempo nas séries iniciais, do Ensino Fundamental, a partir de experiência com a construção de maquete da comunidade quilombola Cafundó, localizada em Salto de Pirapora, SP, com estudantes do $7^{\circ}$. Semestre, do Curso de Pedagogia. O objetivo foi refletir a respeito da importância da formação docente para a construção dessas cetgorias tão importantes para os conhecimentoshistóricos e geográficos dos próximos ciclos.

O trabalho com a maquete e as narrativas coletadas em trabalho de campo, junto à comunidade quilombola, constituíram experiência extremamente rica, propiciando reflexões sobre o papel da geografia e da história, nas séries iniciais, como disciplinas que iniciam os conceitos inerentes a elas. Procurou-se propor a construção das noções de espaço e tempo como atributos antropológicos desenvolvidos ao longo de todo o processo de relação humana com a natureza, constituindo-se como práticas espaciais que se tornam complexas no mundo contemporâneo, sendo que a escola se torna responsável por construir experiências didático pedagógicas que sejam significativas para a compreensão da sociedade existente.

Outra metodologia importante foi o uso da História Oral que permitiu o narrador expor as suas principais memórias, as que eles julgaram importantes. Avaliações foram feitas com os/as estudantes sobre o projeto:

Entendemos com isso, a importância do registro da história de vida de indivíduos integrantes da comunidade como um exercício de aproximação e afirmação da dinâmica de funcionamento da comunidade e até mesmo para confronto com ideais e testemunhos já escritos e estudados sobre a comunidade, que, às vezes, podem não ser fieis à realidade vivida pela comunidade (Estudante A).

Assim, concluímos e entendemos as transformações que já ocorreram como consequência da luta da comunidade negra por seus direitos de igualdade e contra toda forma de preconceito, mas acreditamos que é necessária ainda a 
superação dessa história de marginalização das populações afrodescendentes através da aprendizagem entre brancos e negros, entre as trocas de conhecimento e as quebras de desconfiança. E acreditamos, além disso, no espaço da escola como possível promoção e discussão dessas relações existentes entre culturas diferentes e as possibilidades de transformação de tal realidade (Estudante B).

A criação da linguagem da senzala cupópia é a resistência do povo negro escravizado que ainda existe graças ao sentido de pertencimento e de identidade dos seus descendentes, que lutaram contra as dificuldades para enfrentar os interesses econômicos, para a manutenção da terra de seus antepassados, da sua linguagem, ou seja, de sua cultura, em um movimento contra hegemônico de extrema dificuldade (Estudante C).

Assim, chegamos ao entendimento de que as representações são parte da formação do sujeito, se vinculando aos espaços sociais, da família, da escola e do lugar em que a criança vive, onde esta passa a constituir as noções de mundo e aprende a conviver com as diferenças. Essas noções são apreendidas no plano da vivência e das representações; na escola, é possível repensar as fragmentações de nossas formações e constituir caminhos que possibilitem a articulação das noções de espaço e tempo nos anos iniciais do ensino fundamental que se complexizam durante a escolaridade, construindo noções, também, de alteridade.

O aprendizado do mapa passa por compreender as noções de espaço e tempo, presentes na vida cotidiana. Por isso, o mapa, também, deve ser articulado com os conteúdos da vida social, provocando a visibilidade de sujeitos silenciados na história da formação do território nacional. Trata-se de usos da cartografia como metodologia significativa da presença das identidades e das diferenças. Constitui-se como processo importante para a educação para as relações étnicas e raciais no âmbito escolar. Nesse sentido, refletindo sobre a perda da experiência social que todos vivenciamos, segundo as prescrições instaladas mediante as representações, ideologias e ilusões do espaço e tempo hegemônicos, que envolvem a sociedade contemporânea, a escola pode buscar metodologias a partir dos corpos e das relações espaciais próximas, tornando visíveis as diferentes espacialidades e as singularidades existentes.

\section{NOTAS}


BRASIL. Ministério da Educação e Cultura. Parâmetros Curriculares Nacionais: história, geografia/ Secretaria de Educação Fundamental. - Brasília: MEC/SEF, 1997.

Ii BRASIL. Ministério da Educação e Cultura. Base Nacional Comum Curricular. Brasília/MEC/UNDIME, 2018.

iii BRASIL. Lei $\mathrm{n}^{\circ}$ 11.645. Altera a Lei $\mathrm{n}^{\circ}$ 9.394, de 20 de dezembro de 1996, modificada pela Lei $\mathrm{n}^{\circ} 10.639$, de 9 de janeiro de 2003, que estabelece as diretrizes e bases da educação nacional, para incluir no currículo oficial da rede de ensino a obrigatoriedade da temática "História e Cultura Afro-Brasileira e Indígena". Diário Oficial da República Federativa do Brasil, Brasília, 2008.

iv $\mathrm{O}$ circuito dos afetos é o título do livro de Vladimir Safatle, em que o autor analisa o medo como dispositivo social, fundamento do contrato social de viés hobbesiano. Insiste na ideia de desamparo dos sujeitos como fonte de busca das imagens protetoras de líderes imaginários, resultando em mais dependência psíquica e rejeição ao outro, o diferente, como fuga da desposessão: "Entretanto, o que está sempre em pauta nesse livro é a falácia de tal construção, que orienta a vida política há séculos. Dentro desses moldes, o Estado transforma os sujeitos em figuras carentes da tutela de um grande e poderoso pai. A questão que Safatle insiste em colocar é: por que o desamparo seria algo a se evitar? Recorrendo aos escritos de Freud, declara de modo incisivo que é do desamparo que derivam a emancipação e a coragem para se apresentar nu diante das possibilidades da vida. Afirmando-o, o sujeito abre-se para os vínculos sociais e coloca-se diante das indeterminações próprias ao desejo" (PARENTE, A. A. M. Lacuna. Uma Revista de Psicanálise. Resenha. n 1. 22 de maio de 2016)

${ }^{v}$ LEFEBVRE, Henri. A produção do espaço. Trad. Doralice Barros Pereira e Sérgio Martins (do original: La production de l'espace. 4e éd. Paris: Éditions Anthropos, 2000). Primeira versão: início - fev. 2006. A tradução está disponível em: https://docero.com.br/doc/x8sx5 <acesso em 28 mar 2019>

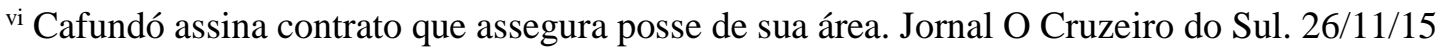
José Antônio Rosa. Disponível em:

https://www2.jornalcruzeiro.com.br/materia/658114/cafundo-assina-contrato- que-assegura-possede-sua-area <acesso em 31 mar 2020>.

vii Entrevista realizada com a moradora do Cafundó, Regina, no dia 24/04/2014, pela estudante, Laíne Horta.

\section{REFERÊNCIAS BIBLIOGRÁFICAS}

ALBERTI, V. Histórias dentro da História. PINSKY, C. B. (org.). Fontes Históricas. 3. ed. São Paulo: Contexto, 2014, p. 154-202.

ALMEIDA, R. D. de. Do Desenho ao Mapa. Iniciação Cartográfica na Escola. SP: Contexto, 2003.

FREUD, S. O Mal-Estar da Civilização. SP (1929, 2011): SP: Penguin e Cia. das Letras, 2011.

LEFEBVRE, H. La Production de l'Espace. Paris: Anthropos, 2000.

LIMA, . C. (org.) Teoria da Cultura de Massa. SP: Paz e Terra, 2000. 
MENESES, U. T. B. de. A História, cativa da memória? Para um mapeamento da memória no campo das Ciências Sociais. Revista do Instituto de Estudos Brasileiros/USP, São Paulo, n. 34, p. 9-24, 1992. Disponível em: <http://200.144.255.123/Imagens/Revista/REV034/Media/REV34-01.pdf〉. Acesso em: 21 fev. 2016.

MEZAN, R. Psicanálise, judaísmo: ressonâncias. Campinas, SP: Ed. Escuta, 1986. ps. 44-49.

OLIVEIRA, Reinaldo José de. Territorialidade Negra e Segregação Racial na cidade de São Paulo - a luta por cidadania no século XX. São Paulo, Editora Alameda, 2016.

PARENTE, A. A. M. Lacuna. Uma Revista de Psicanálise. Resenha. n 1. 22 de maio de 2016.).

SAFATLE, V. O Circuito do Afetos. Corpos políticos, desamparo e o fim do indivíduo. Belo Horizonte, MG: Autêntica, 2016.

SANTOS, M. A Natureza do Espaço. Técnica e Tempo. Razão e Emoção. SP: Edusp, 2006. 1992: a redescoberta da Natureza. Revista do Instituto de Estudos Brasileiros/USP. 6 (14), São Paulo, 1992. ps. 95-106.

SANTOS, Mariza Fernandes dos. A Temática Racial nas teses e dissertações defendidas em Programas de Pós-Graduação em Geografia no Brasil (1987-2018). Revista da Associação Brasileira de Pesquisadores/as Negros/as. v.12, número Especial, p.54-77, março de 2020. ISSN 2177-2770. Disponível em: 〈https://abpnrevista.org.br/index.php/site/article/view/854>. Acesso em: 17 set. 2020

SILVA, L. B. A Construção da Identidade e do Território no Quilombo Cafundó; Monografia; Universidade Estadual Paulista Júlio de Mesquita Filho - UNESP, 2011.

SILVA, T. T. da. et al. (org.) A produção social da identidade e da diferença. SILVA, T. T. da. et al. Identidade e Diferença. A perspectiva dos Estudos Culturais. Petrópolis, RJ: Vozes, 2000. ps. 73-103.

VIGOTSKY, L. S. Pensamento e Linguagem. SP: Martins Fontes, 2011.

VOGT, C., FRY, P. A África no Brasil: Linguagem e sociedade. São Paulo: Cia. das Letras, 1996.

Recebido em: 22/09/2020

Aceito em: 30/10/2020 